\title{
Oxygen Saturation Measurement
}

National Cancer Institute

\section{Source}

National Cancer Institute. Oxygen Saturation Measurement. NCI Thesaurus. Code C60832.

The measurement of the ratio of oxygenated hemoglobin to total hemoglobin in the blood. 